\title{
MUCOLYTIC ENZYME SYSTEMS. XI. HYALURONIDASE IN- HIBITOR AND SERUM MUCOPROTEINS IN PATIENTS WITH LIPOID NEPHROSIS AND ACUTE GLOMERULONEPHRITIS ${ }^{1}$
}

\author{
BY VINCENT C. KELLEY, 2 ROBERT A. GOOD, 8 AND DAVID GLICK, wITh THE \\ TECHNICAL ASSISTANCE OF MARY J. OCHS
}

(From the Departments of Pediatrics and Physiological Chemistry, University of Minnesota Medical School, Minneapolis)

(Submitted for publication June 19, 1950; accepted, August 16, 1950)

Previous reports from these laboratories have indicated that serum levels of the non-specific hyaluronidase inhibitor and of certain acid mucoprotein fractions are elevated in the acute phase of a wide variety of diseases of both men and animals $(1-6)$. In the course of these investigations elevations of the serum levels of both mucoproteins and hyaluronidase inhibitor were observed in a few patients suffering from acute glomerulonephritis. In addition it was noted that patients with lipoid nephrosis, although exhibiting similar elevations in hyaluronidase inhibitor, had decreased serum mucoprotein concentrations (7). The interesting relationships between these two "acute phase" reactions under the circumstances of renal disease in childhood provoked a more detailed study, which is the subject of the present report.

\section{MATERIAL AND METHODS}

The methods employed in the estimation of serum mucoproteins, preparation of hyaluronic acid and hyaluronidase, and determination of hyaluronidase inhibitor have been described in detail $(1,6,8)$. Determination of mucoprotein tyrosine was routinely employed as an indication of the level of the serum mucoproteins in the manner described by Winzler, and associates (9). Serums were obtained by venipuncture of patients in the fasting state. The blood was centrifuged at 2,500-3,000 revolutions per minute for 15-20 minutes and the serum was stored at $-30^{\circ}$ C. until used.

The term "active lipoid nephrosis" as employed in this paper is used to describe the clinical entity characterized by marked anasarca, ascites, albuminuria, hypoproteine-

1 This work was supported by grants from the Division of Research Grants and Fellowships of the National Institutes of Health, United States Public Health Service, Bethesda, Maryland, and the Medical Research Fund of the Graduate School, University of Minnesota.

2 Swift Research Fellow. Present Address: Department of Pediatrics, University of Utah.

8 Helen Hay Whitney Fellow. mia and hyperlipidemia in the absence of hypertension and hematuria. Under the heading of acute glomerulonephritis are included children suffering with their first attack of renal disease characterized by hematuria, albuminuria, fever, and cylindruria. In addition, some of these patients showed white blood cells in the urine, arterial hypertension, oliguria and elevated blood urea nitrogen. Those patients classified as convalescent glomerulonephritis are children who were seen at the University of Minnesota Hospital during the acute phase of their illness and who were being followed in the Outpatient Department after disappearance of the symptoms of their acute disease.

\section{OBSERVATIONS}

In Table $\mathrm{I}$ are included the data summarizing the alterations of hyaluronidase inhibitor and serum mucoproteins observed in 20 patients with lipoid nephrosis. In these cases the mean serum hyaluronidase inhibition was $48 \%$ and the mean mucoprotein tyrosine value was $1.7 \mathrm{mg} \%$. When these values are compared to those for normal children $(5,6)$ it is seen that the mean inhibitor level in the serums of these patients was over twice as great as the mean value in normal children while the mean mucoprotein level was only $68 \%$ of that observed in the normals.

Some observations of interest were made when the hyaluronidase inhibitor and mucoprotein levels of patients with lipoid nephrosis were measured serially during the course of the illness. It was found, for example, that the inhibitor remains elevated following spontaneous diuresis and temporary clinical remission. This relationship of the inhibitor to the state of activity of nephrosis obtained in cases 3 and 12 (Table I). Both of these small boys have had diureses and have been edemafree for one year. In spite of this clinical improvement, activity of the disease process is signaled by a persistent and pronounced albuminuria. 
In patient No. 3 the hyaluronidase inhibitor level one year after the clinical remission continued to be elevated and a value of $38 \%$ inhibition was found as compared to $49 \%$ at the height of the illness and the normal value of $21.5 \pm 0.71$. $\mathrm{Pa}$ tient No. 12 likewise showed continued elevation of inhibitor as long as one year after remission of clinical symptoms, $45 \%$ inhibition being found on the more recent determination as compared to $46 \%$ during the period of maximal symptomatology. These data suggest that not only the persistent albuminuria, but also the elevated hyaluronidase inhibitor during the period of clinical quiescence in lipoid nephrosis is evidence of persistent activity of underlying disease processes.

On the other hand, in patients whose clinical and laboratory studies indicated more complete remission of the disease, the hyaluronidase inhibitor levels were found to fall within the normal range. Two patients who have been entirely free of symptoms for two years, and one patient free of symptoms for six years, showed values of $22 \%, 22 \%$ and $17 \%$, respectively. Albuminuria has likewise

TABLE I

Hyaluronidase inhibitor and serum mucoprotein levels in patients with active lipoid nephrosis

\begin{tabular}{|c|c|c|c|c|}
\hline Case No. & Age & Sex & HI & MPT \\
\hline $\begin{array}{r}1 \\
2 \\
3 \\
4 \\
5 \\
6 \\
7 \\
8 \\
9 \\
10 \\
11 \\
12 \\
13 \\
14 \\
15 \\
16 \\
17 \\
18 \\
19 \\
20\end{array}$ & $\begin{array}{r}5 \\
3 \\
2 \\
10 \\
4 \\
4 \\
4 \\
2 \\
3 \\
5 \\
9 \\
6 \\
6 \\
6 \\
5 \\
3 \\
2 \\
2 \\
4 \\
3\end{array}$ & $\begin{array}{l}\mathbf{M} \\
\mathbf{F} \\
\mathbf{M} \\
\mathbf{M} \\
\mathbf{M} \\
\mathbf{M} \\
\mathbf{F} \\
\mathbf{F} \\
\mathbf{M} \\
\mathbf{M} \\
\mathbf{M} \\
\mathbf{M} \\
\mathbf{M} \\
\mathbf{M} \\
\mathbf{F} \\
\mathbf{F} \\
\mathbf{M} \\
\mathbf{F} \\
\mathbf{F} \\
\mathbf{M}\end{array}$ & $\begin{array}{l}37 \\
62 \\
49 \\
47 \\
68 \\
59 \\
69 \\
50 \\
44 \\
44 \\
44 \\
46 \\
47 \\
30 \\
42 \\
53 \\
58 \\
34 \\
41 \\
38\end{array}$ & $\begin{array}{l}1.7 \\
1.3 \\
1.4 \\
0.9 \\
1.1 \\
1.5 \\
1.1 \\
1.4 \\
1.6 \\
1.1 \\
1.6 \\
1.9 \\
1.8 \\
2.1 \\
4.2 \\
2.8 \\
2.1 \\
2.2 \\
1.2 \\
1.0\end{array}$ \\
\hline Mean & - & - & 48 & 1.7 \\
\hline $\begin{array}{l}\text { Std. error } \\
\text { of mean }\end{array}$ & - & - & 2.3 & 0.17 \\
\hline $\begin{array}{l}\text { Normals: } \\
\text { Mean } \\
\text { Std. error of } \\
\text { mean }{ }^{*}\end{array}$ & & & $\begin{array}{r}21.5 \\
0.71\end{array}$ & $\begin{array}{l}2.5 \\
0.06\end{array}$ \\
\hline
\end{tabular}

* References 5, 6 . disappeared and no evidence of renal impairment can be detected. The prognosis of these children, on the basis of past clinical experience, may be considered to be fairly good. Still another patient (case 11, Table I), has shown a return of the hyaluronidase inhibitor to normal following clinical remission of symptoms of lipoid nephrosis. Unlike patients 3 and 12 (Table I), this child has had a complete remission of symptoms and appears to be well at the present time. These data indicate that the hyaluronidase inhibitor level of the serum is elevated in consequence of the activity of the disease process in lipoid nephrosis, elevations being maintained in the face of incomplete remissions and a return to normal levels signifying abatement of the disease process.

The serum mucoprotein concentrations in patients with active lipoid nephrosis are usually depressed to subnormal values. However, very early in the course of the disease, and also late in the course of the disease, the mucoprotein level may be above normal. One patient (case 15, Table I), studied early in the course of her first nephrotic episode, had an elevated serum mucoprotein tyrosine value of $4.2 \mathrm{mg} \%$. Another patient (case 18, Table I), when first seen by us early in the course of her first nephrotic episode, had a serum mucoprotein tyrosine of $2.2 \mathrm{mg} \%$. When she was seen two and one half months later, after her disease had become well established, the value was low (0.9 $\mathrm{mg} \%)$. Another patient observed very early in the course of her first episode of nephrosis at a time when it was not yet possible to be certain of the diagnosis, had a mucoprotein tyrosine of $3.0 \mathrm{mg} \%$. Three weeks later, following rapid and definite clinical progression, her mucoprotein had decreased to $2.0 \mathrm{mg} \%$. On the other hand, a patient (case 11, Table I), who had shown a low value $(1.6 \mathrm{mg} \%)$ when seen during the active phase of nephrosis, showed an elevation to $3.8 \mathrm{mg} \%$ after being edema-free for one year. Somewhat high mucoprotein levels $(4.4,4.0,4.7 \mathrm{mg} \%)$ were observed in three additional patients following apparently complete remissions of their nephrotic symptoms.

\section{Acute glomerulonephritis}

In the acute phase of glomerulonephritis, increases in both hyaluronidase inhibitor and mucoprotein tyrosine were found (Table II). During 
convalescence from this disease a return toward normal values for both substances was observed.

During the course of this investigation, we were able to make complete serial determinations of hyaluronidase inhibitor and mucoproteins in the serum of three of these patients, and in a fourth case serial measurements were instituted only after the most acute phase of the disease had passed. Figure 1 is an illustration of the data obtained from a typical case. In this figure the curves describing the temperature course, and values of the erythrocyte sedimentation rate are compared to those representing the serum concentrations of hyaluronidase inhibitor and mucoprotein tyrosine. It is apparent from these data that increases in hyaluronidase inhibitor and mucoprotein tyrosine reflect the activity of the disease process in acute nephritis and that clinical recovery is accompanied by return of the levels to normal. Observations on this patient, as well as on the three others studied in this way, indicated that the hyaluronidase inhibitor activity was the first of the serum alterations to return to normal, and that this event was followed in turn by the return to normal of the serum mucoprotein value and the erythrocyte sedimentation rate. It was further observed that in these few patients, subnormal levels of hyaluronidase inhibitor characterized convalescence from
TABLE II

Hyaluronidase inhibitor and serum mucoprotein levels in patients with acute glomerulonephritis

\begin{tabular}{|c|c|c|c|c|c|c|}
\hline \multirow{2}{*}{ Case no. } & \multirow{2}{*}{ Age } & \multirow{2}{*}{ Sex } & \multicolumn{2}{|c|}{ Acute phase } & \multicolumn{2}{|c|}{$\begin{array}{c}\text { Convalescent } \\
\text { phase }\end{array}$} \\
\hline & & & HI & MPT & HI & MPT \\
\hline $\begin{array}{r}1 \\
2 \\
3 \\
4 \\
5 \\
6 \\
7 \\
8 \\
9 \\
10 \\
11 \\
12 \\
13\end{array}$ & $\begin{array}{r}14 \\
6 \\
13 \\
12 \\
7 \\
3 \\
13 \\
11 \\
9 \\
9 \\
14 \\
9 \\
14\end{array}$ & $\begin{array}{l}\mathbf{M} \\
\mathbf{M} \\
\mathbf{M} \\
\mathbf{F} \\
\mathbf{M} \\
\mathbf{M} \\
\mathbf{M} \\
\mathbf{F} \\
\mathbf{M} \\
\mathbf{M} \\
\mathbf{M} \\
\mathbf{M} \\
\mathbf{M}\end{array}$ & $\begin{array}{l}51 \\
29 \\
48 \\
-42 \\
34 \\
- \\
56 \\
- \\
44 \\
-\end{array}$ & $\begin{array}{l}7.8 \\
7.5 \\
3.7 \\
2.4 \\
2.8 \\
2.7 \\
4.8 \\
4.8 \\
5.9 \\
4.7 \\
4.7 \\
-\end{array}$ & $\begin{array}{l}- \\
\overline{-} \\
17 \\
25 \\
\overline{-} \\
\overline{18} \\
\overline{-} \\
\overline{17} \\
18\end{array}$ & $\begin{array}{l}- \\
\overline{-} \\
3.4 \\
2.2 \\
- \\
\overline{-} \\
3.3 \\
- \\
2.5 \\
2.9\end{array}$ \\
\hline Mean & - & - & 43 & 4.7 & 19 & 2.9 \\
\hline $\begin{array}{l}\text { Std. error } \\
\text { of mean }\end{array}$ & - & - & 3.3 & 0.52 & 1.3 & 0.09 \\
\hline
\end{tabular}

glomerulonephritis just as was found to be the case in rheumatic fever (5).

\section{DISCUSSION}

Observations of elevated hyaluronidase inhibitor and mucoprotein levels in the serum of patients with acute glomerulonephritis are in keeping with previous data reported from these labora-

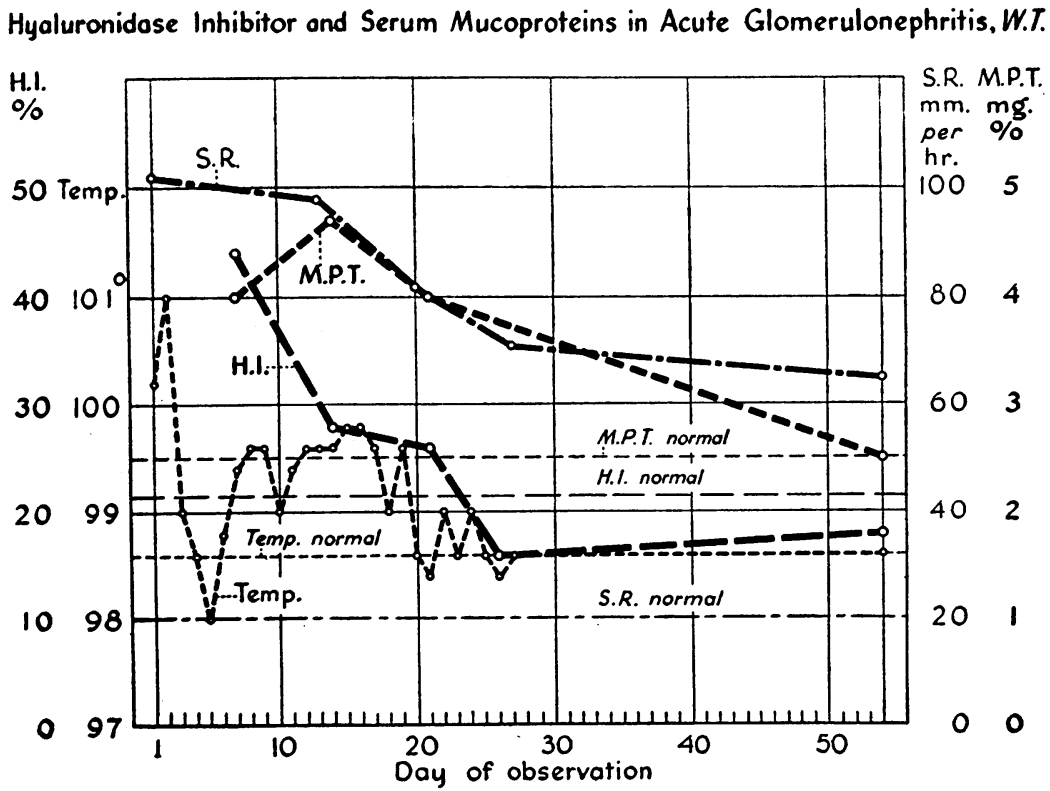

FIG. 1. 
tories, indicating that increases in the serum concentrations of these substances reflect the activity of certain disease processes. In the study of glomerulonephritis the same correlation between hyaluronidase inhibitor and mucoprotein levels previously described (1-6) was observed. Because of this correlation and the parallelism in the rise and fall of the levels of these substances in disease, the possibility was considered that the mucoproteins and the hyaluronidase inhibitor might be identical. Careful study, however, revealed that this was not the case (7). Especially pertinent to this argument was the finding that in patients suffering from lipoid nephrosis, marked elevations in the hyaluronidase inhibitor activity of the blood were found in the presence of marked reduction of the mucoprotein concentration. This finding, confirmed and extended by the data presented here, is probably best explained on the basis of the permeability of the kidneys to protein molecules of relatively small size. Thus, it appears that in this disease the mucoproteins, which are probably small molecules in comparison to other serum protein molecules $(9,10)$, leak through the damaged glomerular capillaries resulting in a reduction of serum level in much the same fashion as occurs with the serum albumins.

That mucoprotein values might be high in the serums of patients with lipoid nephrosis were it not for this glomerular leakage, seems to be indicated by certain findings reported here. In the first place it has been found in our laboratories that nephrotic children incorporate methionine into their serum proteins more rapidly than do normal children (11). In spite of this evidence of rapid protein production, these children are characteristically hypoproteinemic. It appears that the excessive loss of protein in the urine of these patients is sufficient to deplete their protein supplies even in the face of accelerated production. It seems likely from data presented here that a similar relationship of protein formation to depletion obtains with respect to the serum mucoproteins as well. In several patients elevation in serum mucoprotein levels was noted at the time of the first clinical evidence of lipoid nephrosis and a reduction did not occur until the disease had become firmly established. Still further, it was found that remission of the nephrotic symptoms was often accompanied by increases of serum mu- coprotein concentrations. In the four patients upon whom this return to normal or elevated levels of mucoprotein was observed, albuminuria had been minimal or absent for a considerable period and it may be reasoned that mucoprotein was no longer being spilled into the urine. This evidence of increase of serum mucoproteins, both early and late in the course of lipoid nephrosis, suggests that their rate of production might, indeed, be increased during the active phase of this disease.

It is interesting that in lipoid nephrosis the hyaluronidase inhibitor level does not return to normal when a patient simply has a diuresis and temporary remission of symptoms, but that, when patients show evidence of more permanent remissions a return to normal occurs. In one patient, who has been symptom-free for a period of six years, the inhibitor concentration was found to be slightly below normal. It seems likely from the data presented in this paper that the hyaluronidase inhibitor level might furnish an additional objective criterion for prognosis in lipoid nephrosis.

The lack of specificity of either of these serum alterations minimizes the possibility of diagnostic usefulness. One patient diagnosed clinically as glomerulonephritis, who showed marked increase of both hyaluronidase inhibitor and mucoprotein in the serum, was shown at post mortem to be suffering from periarteritis nodosa. Obviously, these studies would be of little value in differentiating rheumatic fever and glomerulonephritis, since elevations of both occur in both diseases. No studies have been made of the mucoprotein and hyaluronidase inhibitor in other diseases that must be considered in the differential diagnosis of acute glomerulonephritis, but it seems quite unlikely from the data already at hand that these determinations will be diagnostically useful. The principal usefulness of studies of this type would apparently be in furnishing objective evidence of the state of activity of disease processes such as lipoid nephrosis, glomerulonephritis, and rheumatic fever.

The patients with acute glomerulonephritis, whose serums were studied repeatedly throughout their illness, exhibited, as was previously pointed out in the instance of rheumatic fever $(5,6)$, a striking correlation between disease activity and the levels of hyaluronidase inhibitor and muco- 
protein in the serum. It was also found that the convalescent and inactive states of glomerulonephritis, similarly to those of rheumatic fever, are characterized by concentrations of hyaluronidase inhibitor somewhat lower than normal. The significance of this observation is not immediately apparent, but it might be interpreted as evidence that here, as well as in rheumatic fever, a genetic factor is begetting this biochemical expression.

\section{SUMMARY}

1. The levels of non-specific hyaluronidase inhibitor and certain mucoproteins in the serums of patients with lipoid nephrosis and acute glomerulonephritis were studied.

2. Elevations of the mucoproteins and hyaluronidase inhibitor were regularly found during the acute phase of glomerulonephritis with a return to normal levels during convalescence.

3. Elevated values of hyaluronidase inhibitor and depressed values of mucoproteins were found in the serums of patients with active lipoid nephrosis. A return to normal levels signified complete remission of the disease process while persistent elevation of hyaluronidase inhibitor following diuresis was found when remissions were incomplete.

\section{BIBLIOGRAPHY}

1. Glick, D., and Gollan, F., Mucolytic enzyme systems. I. Inhibition of hyaluronidase by serum in poliomyelitis. J. Infect. Dis., 1948, 83, 200.
2. Grais, M. L., and Glick, D., Mucolytic enzyme systems. II. Inhibition of hyaluronidase by serum in skin diseases. J. Invest. Dermat., 1948, 11, 259.

3. Hakanson, E. Y., and Glick, D., Mucolytic enzyme systems. III. Inhibition of hyaluronidase by serum in human cancer. J. Nat. Cancer Inst., 1948, 9, 129.

4. Grais, M. L., and Glick, D., Mucolytic enzyme systems. VI. Inhibition of hyaluronidase by serum in infectious diseases. J. Infect. Diseases, 1949, 85, 101.

5. Good, R. A., and Glick, D., Mucolytic enzyme systems. IX. Nonspecific hyaluronidase inhibitor in rheumatic fever. J. Infect. Dis., 1950, 86, 38.

6. Kelley, V. C., Good, R. A., and McQuarrie, I., Serum mucoproteins in children in health and disease with special reference to rheumatic fever. Pediatrics, 1950, 5, 824.

7. Glick, D., Good, R. A., Kelley, V. C., Winzler, R. J., and Mehl, J. W., Lack of identity of hyaluronidase inhibitor and certain mucoproteins in blood serum. Proc. Soc. Exper. Biol. \& Med., 1949, 71, 412.

8. Wattenberg, L. W., and Glick, D., Mucolytic enzyme systems. VII. Effects of tissue extracts and body fluids, certain steroids, and hemoglobin derivatives on hyaluronidase activity. J. Biol. Chem., 1949, 179, 1213.

9. Winzler, R. J., Devor, A. W., Mehl, J. W., and Smyth, I. M., Studies on the mucoproteins of human plasma. I. Determination and isolation. J. Clin. Invest., 1948, 27, 609.

10. Winzler, R. J., and Smyth, I. M., Studies on the mucoproteins of human plasma. II. Plasma mucoprotein levels in cancer patients. J. Clin. Invest., 1948, 27, 617.

11. Kelley, V. C., Ziegler, M. R., Doeden, D., and McQuarrie, I., In preparation. 